\title{
An exploratory study of the barriers and facilitators to the implementation of community health worker programmes in conflict-affected South Sudan.
}

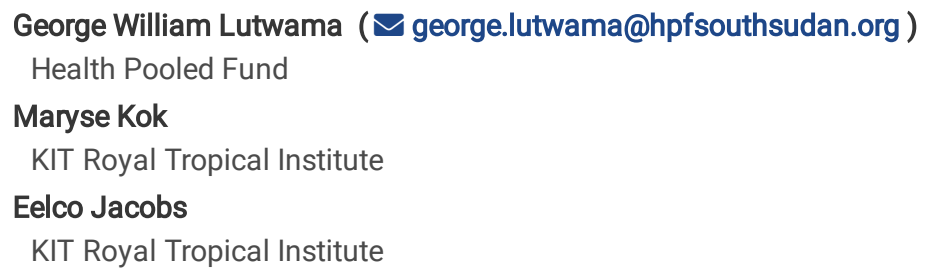

Keywords: Boma health initiative, Boma health worker, Conflict-affected, Community health worker, Health Pooled Fund, South Sudan

Posted Date: March 1st, 2021

DOI: https://doi.org/10.21203/rs.3.rs-250849/v1

License: (c) (i) This work is licensed under a Creative Commons Attribution 4.0 International License. Read Full License

Version of Record: A version of this preprint was published at Conflict and Health on November 18th, 2021. See the published version at https://doi.org/10.1186/s13031-021-00422-0. 


\section{Abstract}

Background: Community health workers (CHWs) are crucial for increasing access to health services to communities. Due to decades of conflict and under-funding, access to health care in South Sudan remains severely limited. To improve equitable access to healthcare, the government has introduced "the Boma Health Initiative (BHI)", a strategy to harmonise community health programmes across the country. In order to scale up the $\mathrm{BHI}$, it is necessary to assess the recent $\mathrm{CHW}$ programmes and draw lessons for future implementation. This study aimed to explore the characteristics, barriers, and facilitators to the implementation of CHW interventions in South Sudan between 2011 and 2019.

Methods: The study used a qualitative approach drawing from 26 key informant interviews and a scoping review of 21 Health Pooled Fund (HPF) programme reports from October 2016 to June 2018 and policy documents from 2011 to 2019 . The results were thematically analysed based on a conceptual framework on factors influencing the performance of CHWs.

Results: Funding of $\mathrm{CHW}$ programmes has come from international donors, channelled through non-governmental organisations (NGOs) that have implemented a variety of $\mathrm{CHW}$ programmes. Communities have been participating in the selection of voluntary $\mathrm{CHWs}$, intervention areas, and occasionally in the supervision of activities performed by CHWs. The coordination mechanisms among stakeholders have been weak, leading to wastage and duplication of resources. Although training of $\mathrm{CHWs}$ is done, training duration was short, and refresher-trainings were rare. There were and still are disparities in the type of incentives provided to CHWs. Monitoring and supportive supervision activities have been insufficient; drug misuse and stock-outs were common.

Conclusion: Despite their challenges, CHW programmes can be implemented in conflict-affected South Sudan if the local human capital is leveraged and engaged by NGOs as implementing partners. Robust coordination efforts are required to build synergies among stakeholders for the effective implementation of the BHI strategy.

\section{Background}

South Sudan has experienced nearly continuous violent conflict since $1955[1,2]$ and has some of the worst health indicators in the world. The maternal mortality ratio is estimated to be at 1,150 deaths per 100,000 live births, child mortality at 99 per 1,000 live births, and infant mortality at 65 per 1,000 live births, which can be mostly attributed to preventable causes [3]. The conflict, which has flared up again since 2013, has led to widespread looting and destruction of health facilities. There has been massive displacements of citizens, mostly children and women, to remote areas where basic health services are scarcely available [1, 3]. It is estimated that over 400,000 lives have been lost since 2013 [4].

With government financing for the health sector at less than $4 \%$ - far below the $15 \%$ commitment under the Abuja declaration $[5,6]$, nearly $80 \%$ of the health services are provided by non-governmental organisations (NGOs) [3, 7]. Since 2012, a basic package of health and nutrition services is provided across ten states through contracted NGOs and pooled donor funding [1,3]. This has led to a significant improvement in maternal, newborn, child and reproductive health, albeit from a very low coverage base of $2.6 \%$ for institutional deliveries to $14 \%$ for four or more antenatal care visits [8]. The health service coverage remains low, and access to care is severely hampered, particularly for rural communities [9].

Studies from low- and middle-income countries suggest that community health worker (CHW) programmes can be effective in improving access to care for underserved communities [10, 11]. Following the 2018 Astana declaration on primary health care, there is renewed political commitment and leadership from the United Nations (UN) member states and global organisations to develop people-centred primary health care, building on the principles, gains, and lessons from the Alma Ata Declaration [12]. For several years, CHW programmes in South Sudan have been uncoordinated, and largely led by humanitarian and development partners with an orientation to specific diseases $[13,14]$. In response to the lack of coordination, the Ministry of Health (MoH) launched the Boma Health Initiative (BHI) strategy in March 2017 with the stated goal of striving towards improved access and health coverage $[13,14]$. The BHI uses trained, full-time, salaried CHWs also known as Boma health workers to leverage community participation in promoting ownership and sustainability of health services $[13,14]$.

The $\mathrm{BHI}$ is intended to bridge the gap between health facilities and communities through standardisation of the service packages offered by $\mathrm{CHWs}$, and harmonisation of incentives across the community health programmes [14]. The BHI focuses on child health, safe motherhood, control of communicable and non-communicable diseases, disease surveillance, and reporting on service delivery and vital statistics [13, 14]. It is estimated that approximately $44 \%$ of the population in South Sudan live within reach of health facilities and have consistent access to primary care services $[14,15]$. Moreover, service provision at facility level repeatedly deteriorates during conflicts [16]. In some locations, community-based programmes discontinued due to active mine laying or presence of explosive remnants of the war [1]. Given the BHI's aim to scale up community health in South Sudan it is imperative to draw lessons from previous $\mathrm{CHW}$ programmes and assess them along evidence from community health in comparable settings. The aim of this study was to explore the characteristics, barriers, and facilitators to implementation of CHW programmes in the states supported by the HPF programme, in order to inform further scale-up of the $\mathrm{BHI}$.

\section{Methods}

\section{Study design}


The study followed a qualitative approach using key informant (KI) interviews and a review of the HPF programme reports from October 2016 to June 2018 and policy documents from 2011 to 2019.

\section{Study Setting}

The study was carried out in eight of the ten states, where health service delivery is supported by the HPF. At the Boma level, the services are delivered through $\mathrm{BHI}$ or a primary health care unit. The primary health care centre is located at payam level, and the hospital at county or state level [17]. At the time of the study, the HPF supported primary health care services in 794 health facilities and the initial roll out of the BHI in 23 of 55 counties from six of eight states.

\section{Participants}

The participants were purposefully selected from the MoH, HPF, NGOs, and UN Agencies, based on their current or previous experience in the health sector and community health programmes. This enabled gathering a wide range of perspectives from policy, management, and practice. The end of project reports from the NGOs contracted to implement the second phase of the HPF programme (2016-2018) were also reviewed.

\section{Data Collection And Analysis}

We reviewed the twenty HPF implementing NGOs' reports and relevant policy documents between June and August 2019. The review focused on the characteristics of community health programmes, types of $\mathrm{CHWs}$, types of services offered, challenges faced, and lessons learnt during the implementation. The findings from this review fed into the discussions with the study participants.

We conducted twenty-six interviews in English between 21st August and 19th September 2019 using a semi-structured interview guide. Seventeen interviews were face-to-face, three via Skype and six by telephone. On average, the interviews lasted 69 minutes, ranging from 48 to 90 minutes. Table 1 shows the characteristics of the participants.

Table 1

Characteristics of the participants

\begin{tabular}{|lll|}
\hline Item & Category & Number $(\mathbf{N}=\mathbf{2 6})$ \\
\hline Gender & Women & 07 \\
& Men & 19 \\
\hline Organisation & Non-Government & 13 \\
& Ministry of Health (National and State) & 10 \\
& United Nation Agencies & 03 \\
\hline \multirow{2}{*}{ Roles in Organisation } & Coordination and Policy & 08 \\
& Programme management & 07 \\
& Programme implementation & 11 \\
\hline
\end{tabular}

Fifteen participants consented to audio recording of the interviews. The recorded interviews were transcribed verbatim. From the non-recorded interviews, comprehensive notes were taken, and transcripts were finalised thereafter. All interview transcripts were imported into NVivo 12 software (QSR International) and thematically analysed. The coding was done based on predetermined themes adapted from a conceptual framework on factors influencing performance of $\mathrm{CHWs}$ in low- and middle-income countries [18]. This framework identified three major categories of factors that could influence the CHW programmes: contextual, health systems, and intervention design factors.

\section{Ethical Considerations}

Ethical approval was obtained from the KIT Royal Tropical Institute Research Ethics Committee (reference S.107). Informed written consent (for face-to-face) and verbal consent (for Skype and telephone interviews) were obtained from the participants, their privacy and confidentiality were assured and respected during and after the interviews. No incentives were provided for participation in the study. The HPF senior leadership granted permission to access and review the programme reports.

\section{Results}

\section{Characteristics of community health worker programmes}

The health focus of CHW programmes as cited by study participants were: integrated community case management (iCCM); immunisation outreaches; water, sanitation, and hygiene promotion; neglected tropical diseases (NTD) (e.g. preventive chemotherapy and guinea worm disease 
surveillance); HIV/AIDS behaviour change communication; referrals of patients; and screening for malnutrition.

The information from the HPF reports revealed that programme activities were mostly in the primary care facilities. To a lesser extent, the implementing NGOs used community-led approaches to increase demand for primary care services. These approaches included the forming and the training of health facility and Boma health committees (BHCs) to provide oversight in implementing the primary care activities. Other approaches were community mobilisation and promotion by voluntary $\mathrm{CHWs}$, mother-to-mother support groups, and school health clubs; the sourcing of local materials to renovate health facilities; the distribution of misoprostol to prevent postpartum haemorrhage, and using $\mathrm{CHWs}$ to treat specific diseases of children under five years of age.

\section{Intervention Design Factors}

\section{Intervention design factors}

\section{Human resources management}

\section{Characteristics of community health workers}

The description of the types and characteristics of the CHWs (all volunteers) that were working under the community health programmes are presented in Table 2.

Table 2

Types and tasks of the community health workers

\begin{tabular}{|lll|}
\hline $\begin{array}{l}\text { Types of voluntary } \\
\text { CHW }\end{array}$ & Programme they worked for & Tasks they were involved in \\
$\begin{array}{l}\text { Community based } \\
\text { distributors (CBDs) }\end{array}$ & $\begin{array}{l}\text { Integrated community case management } \\
\text { (iCCM) and Community case management } \\
\text { (CCM) }\end{array}$ & $\begin{array}{l}\text { Treatment of children under five for pneumonia, malaria, diarrhoea, health } \\
\text { education on child health, and screening for malnutrition and referrals }\end{array}$ \\
$\begin{array}{l}\text { Community drug } \\
\text { distributors (CDDs) }\end{array}$ & Neglected tropical diseases (NTD) & $\begin{array}{l}\text { NTD drug distribution, community mobilisation and awareness raising, } \\
\text { and referral of suspected NTD cases to the health facilities }\end{array}$ \\
\hline $\begin{array}{l}\text { Community } \\
\text { nutritional } \\
\text { volunteers (CNVs) }\end{array}$ & Nutrition & $\begin{array}{l}\text { Screening for malnutrition, nutrition education and referral of malnutrition } \\
\text { cases from community to health facilities, and follow-up of children } \\
\text { discharged. }\end{array}$ \\
$\begin{array}{l}\text { Home Health } \\
\text { Promoters (HHPs) }\end{array}$ & $\begin{array}{l}\text { Maternal and child health and Water, } \\
\text { Sanitation and Hygiene }\end{array}$ & $\begin{array}{l}\text { Health education, distribution of misoprostol for prevention postpartum } \\
\text { haemorrhage, mobilising for health campaigns }\end{array}$ \\
$\begin{array}{l}\text { Traditional Birth } \\
\text { Attendants (TBAs) }\end{array}$ & Maternal and child health & $\begin{array}{l}\text { Some community deliveries, referral of mothers for skilled birth } \\
\text { attendance, health education }\end{array}$ \\
$\begin{array}{l}\text { Mother-to-mother } \\
\text { support groups } \\
\text { (M2MSG) }\end{array}$ & Nutrition & $\begin{array}{l}\text { Support mothers and their children under five on healthy living, follow on } \\
\text { immunisation status of children and antenatal care services. }\end{array}$ \\
\hline
\end{tabular}

\section{Selection and recruitment of community health workers}

Supported by the implementing NGOs and the County Health Department (CHD), the community leaders and the BHCs led the selection of CHWs. For nearly all the $\mathrm{CHW}$ programmes, the selection criteria included being a resident of the area, ability to read and write, being trainable, aged between 18 to 45 years, willing to work as a volunteer, well behaved, and being approved by the community. The participants revealed that in some areas there was favouritism during the recruitment process while in others, it was hard to find literate people. "There are some communities where people selected were not living in those particular Bomas, they (leaders) instead selected people from towns" (KI12, Man, MoH). A few participants mentioned that there was preference for older women as CHWs, since they were more stable in the community than men and younger people, nonetheless they are limited by their education levels. Some participants proposed that the current primary level education requirements for the selection of $\mathrm{CHWs}$ to be relaxed for women to ensure gender equality.

\section{Training of community health workers}

The $\mathrm{CHWs}$ received training and occasionally refresher training sessions. The participants reported variations in the duration of the training sessions, ranging from one day to nine months. For ICCM, the participants reported that the duration of the initial training was six days, and refresher training sessions took three days. With other programmes like on NTDs, the duration of training sessions was one day for the community drug distributors, two days for the supervisors, and five days for the training of trainers.

The participants reported that differences in the duration of training sessions (for the same programmes) across the counties and the implementing NGOs were due to insufficient budget to carry out such activities. For instance, training of home health promoters used to take two or three days in some counties while it took five days in others. The participants mentioned that the refresher training sessions were irregular, either due to lack of 
funds or the neglect by the implementing NGOs. Many CHWs did not have the required education and did not get a chance to practice under the supervision of the linking health facility before their deployment into the community.

The participants cited the use of simple pictorial training materials to facilitate learning. The participants also mentioned that unlike the training materials for iCCM and NTD programmes, the current BHI training materials are bulky, heavily worded, and lack pictographic aspects, which makes it difficult for the low educated CHWs to understand. The participants recommended that after training, the CHWs should be attached to the nearby health facility to have supervised community practice to acquire skills and hands-on experience.

Most participants indicated that iCCM and NTD programmes have training curricula developed by the MoH, with support from partners as illustrated in the following quote: "Currently, UNICEF is supporting the Ministry of Health to revise and develop curriculum and training modules for Boma health workers" (KI12, Man, MoH).

The training programmes for the home health promoters, the BHCs, and the traditional birth attendants, did not have curricula. In this case, the NGOs developed their training materials, which led to variations in the content and the duration of the training sessions. "Under the South Sudan health transformation project in Central and Western Equatoria, we (NGO) developed the training manuals for the village health committees, the home health promoters and the traditional birth attendants in consultation with the State Ministries of Health" (KI19, Man, UN).

\section{Supervision}

From the participants and the HPF reports, it was found that the BHC members and the local community leaders supervised the activities of the CHWs. Other supervisors were community based supervisors (for the iCCM and NTD programmes), the NGO technical staff, the CHD staff, and occasionally staff from the nearby health facilities.

The participants declared that supervision of $\mathrm{CHWs}$ was through monthly joint supervision visits. A few participants mentioned that they used group meetings with the $\mathrm{CHWs}$ to monitor performance. The participants cited that inadequate and infrequent supervision visits were partly due to insecurity, lack of transport, and poor road networks in the counties. For iCCM, there was limited involvement of the CHD in supervising CHWs. Moreover, the nearby health facility staff were not involved in the supervision of community activities, leading to gaps between the community and health facility activities. The participants cited the lack of payam health departments and the occasional dormancy of the BHCs as obstacles to the supervision of CHWs.

\section{Performance appraisal}

Nearly half of the participants mentioned that performance assessment of CHWs was done by comparing CHWs' achievements against the planned activities. Some of the indicators used were the number of patients treated, the number of reports submitted, daily attendances, and the number of community mobilisation sessions conducted. A few participants mentioned that in previous CHW programmes, there was no structured performance assessment framework for CHWs. "Performance management of CHWs is something we (policy makers) have to look into critically as we start Boma health initiative implementation." (KI25, Woman, UN).

\section{Incentives}

The participants mentioned that they offered CHWs both material and financial incentives depending on the programme. Some of the CHWs (e.g., CBDs), received monetary incentives ranging between five to 100 United States dollars per month. In some cases, such as NTD and maternal child health programmes, transport refunds were offered to $\mathrm{CHWs}$ when they attended training and when they accompanied mothers with danger signs to the health facilities.

Some participants mentioned that they provided only material incentives, e.g., soap, sugar, gumboots, raincoats, torches, umbrella, t-shirts, and bicycles, while others provided only training and supervision for motivation. "We (NTD programme) have two layers of volunteers, the ones at the village level, we only train and train...., and keep supervising them, but no other incentive is given..." (KIO2, Man, MoH). Nearly all participants mentioned that there are no separate incentives given to CHWs for referrals since this was part of their routine work. A few participants observed that under $\mathrm{BHI}$, the $\mathrm{CHWs}$ are to receive a salary from the government and incentives from NGOs.

\section{Quality assurance}

\section{Monitoring and evaluation}

For the iCCM and the NTD programmes, the CHWs used pictorial registers and summary forms to collect and report data. The Boma supervisors collected the CHW reports and submitted them to the supporting NGO or CHD offices. At the CHDs, the reports were checked for completeness and entered into the district health information system. Some participants noted that while the CHWs and the supervisors submitted reports, the data quality was questionable. Most participants also reported that the current $\mathrm{BHI}$ reporting tools are complex and are difficult to complete for the illiterate or low educated CHWs.

\section{Community and health links}

The participants reaffirmed that community leaders are involved in several stages of implementation of CHW programmes. The community leaders facilitated the situation analysis, mapping of communities, selection of locations for implementation, selection of volunteers, community 
mobilisation and awareness, and supervision of $\mathrm{CHW}$ activities. The participants acknowledged the relevancy of community sensitisation meetings in programme implementation. These meetings resulted in people having the same understanding of the programme activities and what each party involved will contribute.

In some counties, the implementing NGOs prepositioned the $\mathrm{CHWs}$ ' medical commodities at the nearby health facilities to facilitate the monitoring of and the reporting on drug usage. The health facilities also served as replenishment points of the CHW stock. In other counties, however, the NGOs supplied the medical commodities directly to the CHWs without passing through the CHD or the nearby health facility. The participants indicated that the understaffing and heavy workloads limited the health facility staff's ability to supervise CHW activities.

\section{Communication and coordination}

Some participants cited the importance of quarterly review meetings held by NGOs at the county level as good avenues for disseminating information to and getting feedback from communities. Some BHCs also provided feedback from the communities to health facilities or the CHD, and vice versa. Furthermore, the participants proposed the formation or reactivation and strengthening of BHCs to provide oversight roles in the implementation of community health activities. They stressed that strong coordination and regular information sharing among stakeholders can eliminate duplication of services.

\section{Resources and logistics}

Supplies

CHWs kept the medical commodities, like antimalarial drugs, in metallic boxes at their homes. For the iCCM programme, the NGOs procured and distributed medical commodities to the $\mathrm{CHWs}$ without passing through the $\mathrm{MoH}$. In the NTD programme, the donors procured the drugs, but the distribution was mostly through the $\mathrm{MoH}$ supply chain. The participants reported stock-out of some drugs and commodities resulting from misuse, for example, drugs given to ineligible clients. The participants also mentioned that in some counties, the storage facilities were inadequate, which made it difficult to preposition drugs during adverse weather conditions.

\section{Job aids}

The participants mentioned that $\mathrm{CHWs}$ were supplied with some job aids to facilitate their work. For example, under iCCM, the CHWs had timers, beads, mid-upper arm circumference tapes, and pictorial charts to support health education and the assessment and treatment of children. Some participants mentioned that the use of beads and timers by the uneducated CBDs helped to improve the quality of diagnosis and management of pneumonia among the children under five years of age.

\section{Transport}

The CHWs moved on foot when they were conducting their activities. In the NTD and iCCM programmes, the CHW supervisors were given bicycles to facilitate their movements in the community. At the county and NGO level, a motorcycle or vehicle was allocated to support the supervision and distribution of commodities. Some participants reported that in 2017, the Chinese government donated items to the MoH, which included bicycles to support the community health programmes in the country.

\section{Health Systems Factors}

\section{Governance of community health worker programmes}

The MoH provided oversight over the programmes, but most of the coordination was by donors and the contracted NGOs. One participant mentioned that before 2014, the iCCM programme was not embedded into the MoH health system, and had no funds allocated from the national budget. Other participants mentioned that technical working groups with members from the MoH, implementing NGOs, and the funders played a crucial role in coordinating community health. They were providing technical support to relevant departments of the MoH. For some programmes like for NTDs, the coordination was through the relevant government structures right from the village to the national level.

Nearly all participants referenced insufficient coordination as a limitation to efficient and effective implementation of community health activities. While in some counties, there were coordinated approaches in the implementation of activities, in others, the MoH and NGOs did not always sit together to agree on the modalities (such as the locations) for the implementation, which sometimes led to duplication of services. In some programmes like iCCM, the NGOs were controlling funds meant for implementation, hence, the CHD felt less empowered to monitor the CHW programme activities.

\section{Funding of the community health worker programmes}

The main sources of funds were international donors. The donors frequently cited were: United Kingdom's Department for International Development (DFID) (now Foreign Commonwealth and Development Office (FCDO), United States Agency for international Development (USAID), Canada, and Sweden also (pooled) funding of the HPF programme. Other donors included the Global Fund, the World Bank, the Carter Centre, the African Programme for Onchocerciasis Control (APOC), the European Union, the United Nations (UNICEF and WHO), the German Government, the Kingdom of Norway, and the Republic of China. "I am not sure how much contribution the government [South Sudan] has made towards the community 
health programmes, but the government is providing guidance and leadership" (KI15, Man, UN). Most donors including HPF, channelled funds through NGOs for fear of mismanagement by the government. The participants cited insufficient funding for community health activities compared to the health facility activities. The information from the participants and the HPF reports showed the lack of continuity of some programmes (such as iCCM) once donor funding ended.

\section{Contextual Factors}

\section{Conflict and insecurity}

The participants reiterated that conflicts and insecurity affected the implementation of CHW programmes in the country. Insecurity led to the displacement of communities, looting of medical commodities, and at times death of CHWs. For example, in Nagero County of Western Equatoria State and in Panyijar County in Unity State, insecurity led to the suspension of community health activities. Two participants reported that during the conflict in Panyijar County, the iCCM CBDs continued to provide services to the displaced communities and their hosts.

\section{Adverse weather conditions}

The participants reported that the rainy season rendered many locations inaccessible. This limited not only the movements of the CHWs and their supervisors, but also hampered the supply of medical commodities.

\section{Poor infrastructure}

The participants said that poor road infrastructure in some locations hindered movements of CHWs and their supervisors, the distribution of medical commodities, and made referrals difficult. Some participants acknowledged that although $\mathrm{CHWs}$ were given cell phones for reporting and keeping in touch with their supervisors, the mobile telephone network coverage was limited in rural areas.

\section{Political aspects}

The participants mentioned by introducing $\mathrm{BH}$ in 2016, the government has recognised community health as a vehicle to improve access to health services in the communities where there are no health facilities. A few participants mentioned that during the war for independence, the government with support from NGOs used CHWs to provide health education and first aid in the liberated communities.

\section{Economic aspects}

Some participants mentioned that following the devaluation of the South Sudan currency in 2015, many voluntary CHWs started demanding for financial incentives instead of material incentives. Most CHWs were the breadwinners for their families and therefore needed money to provide for their needs during the economic crisis.

\section{Gender aspects}

Although many community members were said to prefer female CHWs, participants reported that there were more male $\mathrm{CHWs}$ than female ones. This was, according to them, because men are more educated than women. The participants also mentioned that the involvement of women in BHCs was limited despite the requirement that one third of the members should be women.

\section{Community Health Worker Performance}

At the community (end-user) level, many participants mentioned that CHWs promoted community mobilisation and utilisation of some health services. "In our (NGO) programme, the mother-to-mother support groups were an effective tool for behaviour change within the community towards the use of services like for family planning" (KI01, Man, NGO).

Some participants mentioned that CHWs reached areas where no formal health workers from the health facilities could come, and they identified danger signs among mothers and children early, which prompted early referrals. "The communities were testifying to me that iCCM saved the lives of many children and [they] were demanding services to be extended to the other age categories" (KI05, Man, NGO).

The HPF programme reports referenced that community dialogue sessions and advocacy meetings helped to improve uptake of the maternal and child health services. The BHCs contributed to improving water, sanitation, and hygiene activities, and supported health campaigns in the community. Lastly, working with communities helped in organising regular integrated outreach services in remote areas. This improved access to promotive and preventive health services in the community.

\section{Impact Level}

Some participants mentioned that $\mathrm{CHWs}$ working in disease surveillance have helped the country to progress from being the most guinea worm endemic country in the world to the current zero case reporting. "This is a big achievement on the backdrop of the conflicts and challenges you can think of in this country..." (KIO2, Man, $\mathrm{MoH})$.

Most participants reiterated that where there were no health facilities, the iCCM programme increased access to malaria, pneumonia, and diarrhoea treatments in children under five. These might have contributed to the presumed reduction in child deaths related to the three diseases. 


\section{Discussion}

Our findings show that CHW programmes were influenced by a variety of factors which were programme related, while others were contextual and health systems related. The programmes used different types of $\mathrm{CHWs}$, and their tasks were mainly in health education and promotion, treatment of some diseases in the children under five, distribution of drugs for NTDs, and facilitating referrals.

The selection of the most suitable community members to become CHWs is vital to the quality and acceptability of health services provided [19, 20]. Similar to the experience in South Sudan, several studies in other settings have established that CHWs are selected based on community membership, social acceptance, gender, knowledge of the culture and languages, personality, past experience, and the level of education [21-23]. The literacy level in South Sudan is a serious obstacle to the recruitment of CHWs since less than 35\% of men and 19.2\% of women is literate [24]. Working with communities during the selection process is vital because it ensures that the members understand and accept the work of the CHWs $[25,26]$. Although the communities led the selection process, we found instances where the selection criteria [14] were not followed. There was also a preference for married women over men and young women over young men since they are deemed to stably reside in the communities. Brown and colleagues, however, advised not to use either age or marital status as selection criteria [20,25], and it is generally advisable to have a mix of female and male CHWs, depending on the health topics and cultural norms [25, 27, 28].

Our findings reveal differences in the duration of training sessions for $\mathrm{CHWs}$ on similar topics across the counties due to lack of funds and standardised training modules. Elsewhere, studies uncovered variations in the content, quality, length, and training methodologies between $\mathrm{CHW}$ programmes $[25,27,28]$. Researchers have reported cases where $\mathrm{CHWs}$ received training sessions that were insufficient and of poor quality $[23,28$, 29]. Instead, training sessions should be competency-based, to allow the participants to gain the necessary technical and social skills, and the training materials should be in a language understood by the CHWs, preferably with pictographic illustrations [25].

We found that refresher training sessions were only occasionally offered and did not all make use of standardised training material. A study from Uganda concluded that regular refresher training sessions for $\mathrm{CHWs}$ managing multiple infectious diseases were needed since the initial training sessions were not sufficient to ensure CHW performance [30]. Moreover, international guidelines and experiences elsewhere stipulate that training sessions need to be gender sensitive and responsive since women and men might have different literacy levels and often operate under different social expectations $[25,28]$. Some CHW programmes (e.g. for home health promoters and traditional birth attendants) did not have official training curricula. The quality of training, e.g., for $\mathrm{CHWs}$ to understand their roles, the services they will offer, and how to provide them, is a critical factor in the success of any $\mathrm{CHW}$ programme and requires adequate investment [25, 31].

This study found that the supervision of the CHWs was carried out by supervisors from the community, the health system, and the supporting NGOs. The health facilities and CHDs provided minimal supervision to the CHWs, for example in the iCCM programme. This was partly because health workers perceived supervision of the CHWs as additional work that needs to be incentivised. Similar to our findings, a study done in Guinea, Liberia, and Sierra Leone identified weak links between $\mathrm{CHWs}$ and the formal health system as deterrents to effective implementation of community health programmes [32]. Some studies found that during the conflict, the use of community members as $\mathrm{CHW}$ supervisors was crucial in increasing the resilience of the iCCM programme [16,33].

NGOs played an important role in supervising CHWs in the areas where they operated. Supervision should provide opportunities for learning, problem-solving, (community) feedback, and quality assurance. Supervision is an opportunity to assess and strengthen the knowledge and skills of $\mathrm{CHWs}$, thereby improving the quality of service delivery $[25,27,29,31,34,35]$. However, there was inadequate supervision exemplified by infrequent visits due to insecurity, and lack of means of transport. Studies have reported that during conflicts, and where there is insecurity, the frequency of supervision reduces or even stops [16, 36, 37]. A study in Guinea, Liberia, and Sierra Leone also found weak supervision of CHW activities [32]. Additionally, in Rwanda, the infrequent supervisory visits compromised the quality of community health programmes [23].

We found that $\mathrm{CHWs}$ received material and financial incentives to facilitate their work, yet incentives were not harmonised across the programmes. Studies have revealed that $\mathrm{CHWs}$ are usually given small financial incentives such as honorarium, travel allowance, or other irregular payments but are also motivated by non-financial incentives such as social recognition and prestige, an opportunity to gain knowledge and access to medicines that can benefit their families [27, 28, 38]. Whether CHWs should work as volunteers or should be paid a salary is often under debate [27]. WHO recommends that $\mathrm{CHWs}$ should be remunerated based on their task descriptions [25]. Without proper compensation of $\mathrm{CHWs}$, the community health programmes may face high attrition $[25,27,28,39]$.

Our findings show that CHWs' performance in South Sudan is generally assessed based on the activities conducted and the reports submitted. Generally, a lack of performance management frameworks was found. Performance appraisal of the health workforce is fraught with challenges, however, there is a consensus that the ultimate goal should be to improve motivation and performance of workers for better health outcomes [40, 41]. A recent study proposed a framework for $\mathrm{CHW}$ performance measurement and some of the domains include; $\mathrm{CHW}$ incentives, supervision and performance appraisal, data use, data reporting, service delivery, quality of services, CHW absenteeism and attrition, community use of services, experience of services, referrals, and trust [42]. Closely linked to supervision is the quality of reported data.

Our findings show that the $\mathrm{CHWs}$ were reporting on their activities, but the quality of data was regarded as poor.

Page $8 / 13$ 
We found that, despite variation, communities were involved in situation analysis, planning, selection of CHWs, and supervision of community health activities. There is growing consensus that programmes that seek to promote empowerment should involve participation of community members, to offer opportunities for gaining knowledge and skills, confidence, experiences and ability to detect and solve problems [43-47]. Community participation provides people with a sense that members can solve their problems through careful reflection and collective actions [25, $47,48]$. In Ghana, community leaders, trained volunteers and other community members supported health education activities to facilitate skilled birth attendance and contributed land, construction materials, and labour for building health centres [49]. Our findings revealed that in some locations, the BHCs did not exist or were dormant. Given their importance in the BHI strategy, there is need to form or reactivate the committees to ensure ownership and sustainability. Hence, strengthening local governance structures (e.g., the BHCs) and processes, with attention to appropriate representation and inclusion, should be part of the investment in CHW programmes [50].

This study highlights a need for a collaborative relationship between the CHWs and facility staff to ensure accountability, coverage and quality of care. For example in Mozambique, coordination and communication between the CHWs and the formal health workers enhanced accountability towards the community and the health system [51] and in Uganda, improved communication between CHWs and clinicians through m-health improved the quality of care [52].

Our findings reaffirm that $\mathrm{CHW}$ programmes are funded by donors and implemented through NGOs. Kozuki and colleagues reported that there was no funding for iCCM from the national budget. Therefore, once donor funding ceased, the organisation and the structures were left hanging [33]. A study done in Mayendit county in 2017, however, found that when the local authorities have active and responsible roles in the programmes, community engagement is more sustainable [2]. Our findings reaffirm that $\mathrm{CHW}$ programmes were fragmented and lacked a standardised regulatory framework. There was inadequate coordination among the community health programmes in the country. Erismann et al., found similar weaknesses in South Sudan and Haiti and recommended establishing and strengthening coordination mechanisms to avoid creating inequalities that might lead to tension and deterioration in social cohesion [2]. Lehmann and others [50] have suggested that harmonising and integrating donor support is an essential building block to the functionality of any $\mathrm{CHW}$ programme. Hence, $\mathrm{BHI}$ in South Sudan was established to ensure co-ordination and harmonisation of CHW programmes.

Our findings are commensurate with the observation in other fragile and conflict-affected settings where NGOs often create parallel supply chains to ensure the consistent supply of drugs to the NGO supported facilities [16,53]. Yet, our findings also show inadequate facilities for the storage of medical commodities in the health facilities and at county level. There were also reports of drug misuse leading to stock-outs. The shortage of medical commodities, which are mainly supplied by NGOs, can have consequences beyond the immediate supply, such as a reduction in the trust of CHWs by community members and a decline in utilisation of the services $[13,39,47]$. In Guinea, Liberia, and Sierra Leone during the Ebola outbreak, the supply chain, restriction on movement of the NGO staff due to hostilities, community resistance, and closure of some health facilities hampered service delivery [32]. Other studies in Afghanistan and South Sudan reported that severe weather conditions and insecurity along the roads, poor management, and high distribution costs led to stock-outs of the medical commodities $[29,33,36]$.

We identified some contextual factors that affected the previous community programmes and might impact the BHI, such as insecurity, the economy, community, and gender-related issues. Conflicts in Unity and Western Equatoria states led to suspension and even termination of some of the CHW programmes. Some studies from South Sudan demonstrated that in parts of Unity State where there was a conflict, the internally displaced CBDs continued to provide the services to displaced persons and their host communities [2, 33]. In some counties, where weather and security challenges were anticipated, the NGOs and supervisors prepositioned the drugs to last them for longer periods without replenishment. This ensured availability of the drugs and other medical commodities during the crises [33, 36, 54].

While this study did not show a direct relationship between the effects of economic crisis and motivation, the CHWs were reported to prefer financial incentives above material incentives to provide for their families. There were instances in this study where some communities were reported to prefer female CHWs compared to their male counterparts. However, the low level of literacy, especially among women [24], puts them at a disadvantage of being selected as a CHW. Despite the conflicts in the country, the government has made political commitments by introducing the $\mathrm{BH}$ strategy to improve access to healthcare $[13,14]$. This, however, remains hampered by a lack of (public) funds and legislative framework to support CHWs who have no formal public health certification.

The insights from our findings give rise to several policy recommendations. There is a need for the MoH to take a leading role in coordination to ensure ownership and sustainability of the $\mathrm{CHW}$ programme. This can be done through policy dialogues, information sharing, participatory decisionmaking, and resource mobilisation. It is also essential for policymakers to design an incentive structure that will not create a financial burden to the government and the communities. To ensure a strong and functional CHW programme, there is a need for a collaborative relationship between the CHWs and the health facility staff. This will facilitate supervision, enhance accountability, supply of medical commodities and referral of clients. Supervision should be frequent, regular and use standard supervision guidelines with clearly defined objectives to reinforce knowledge, skills, competencies, and motivation. Lastly, a minimum quality of training can be assured through using set guidelines and/or curricula based on the context and education level of the CHWs and the type of work they are expected to perform.

\section{Study Limitations}


This study was subject to several limitations. Participant's bias may have occurred since the participants were either policymakers or programme implementers, which could have resulted in them being less critical about the programmes they were responsible for. The study, however, made a conscious effort to cross-validate and triangulate information from stakeholders with different interests in the matter. The study was carried out at the onset of $\mathrm{BHI}$ implementation; thus, some aspects of the strategy may not have been clear to both the participants and the researchers and certain policy details may have shifted.

The community activities presented in the HPF reports were only those under the programme contractual obligations. The study did not capture the views of $\mathrm{CHWs}$ or community members directly, and, therefore, cannot be taken to represent their experiences. As the BHI is being scaled up, future research should include $\mathrm{CHWs}$ to learn from their experiences. This includes due attention to the power context in which both Boma health workers and citizens operate, influencing CHWs' ability to deliver services and the citizen's ability to access them.

\section{Conclusions}

Despite rampant conflicts in South Sudan, a variety of CHW programmes have been implemented in recent years. Our findings provide insights into the factors influencing these programmes in South Sudan as learnings for the implementation of BHI. Many of the factors were related to the way the programmes were designed, in terms of $\mathrm{CHW}$ tasks, human resources management, community participation, as well as aspects of quality assurance. Others were related to governance, coordination, and funding of $\mathrm{CHW}$ programmes. Although outside the programmes' control, conflict, adverse weather conditions and poor infrastructure affected the programmes. It is important that policy makers evaluate this evidence to enable the successful implementation of the BHI strategy in South Sudan, thereby improving access to and quality of health services in the country, contributing to the universal health coverage. For effective implementation of the $\mathrm{BHI}$ strategy, there is a need for robust coordination and cooperation among stakeholders.

\section{Abbreviations}

AIDS: Acquired Immune Deficiency Syndrome; APOC: African Programme for Onchocerciasis Control; BHC: Boma Health Committee; BHI: Boma Health Initiative; CBD: Community Based Distributor; CDD: Community Drug Distributor; CHD: County Health Department; CHW: Community Health Worker; DFID: Department for International Development; FCDO: Foreign Commonwealth and Development Office; HIV: Human Immune Deficiency Virus; HPF: Health Pooled Fund; iCCM: Integrated Community Case Management; MoH: Ministry of Health; NGO: Non-Governmental Organisation; NTD: Neglected Tropical Diseases; UN: United Nations; UNICEF: United Nations Children's Fund; USAID: United States Agency for International Development; WHO: World Health Organization

\section{Declarations}

\section{Acknowledgements}

We would like to acknowledge all the participants of this study. We appreciate support from the donors of the HPF programme.

\section{Funding}

This study received funding from Health Pooled Fund. HPF is funded by a consortium of donors led by the United Kingdom, Foreign Commonwealth and Development Office (FCDO) (formerly Department for International Development (DFID), and others include the United States Agency for International Development (USAID), the Government of Canada, the Government of Sweden, the Gavi-The vaccine alliance, and the European Union (EU). The views expressed in this article neither do they represent those of the donors nor of the HPF, they are entirely the interpretations of the authors.

\section{Availability of data and materials}

N/A

\section{Authors' contributions}

GWL, MK and EJ conceptualised the study, and developed the research proposal. GWL collected, analysed, and coded the data. GWL drafted the manuscript. MK and EJ reviewed the manuscript and gave critical inputs to finalise the manuscript. All authors read and approved the final manuscript.

\section{Competing interests}

All authors declare that they have no competing interests.

\section{Consent for publication}




\section{Ethics approval and consent to participate}

The study was approved by the Research Ethics Committees of KIT Royal Tropical Institute, Amsterdam, The Netherlands, with approval reference number S.107 in a letter dated $15^{\text {th }}$ August 2019. Informed consent was obtained from all the participants of the study. Permission to access the HPF reports was obtained from the HPF senior leadership in Juba South Sudan.

\section{Author details}

${ }^{1}$ Health Pooled Fund, American Embassy Residency Road, Juba - South Sudan.

${ }^{2}$ KIT Health, Royal Tropical Institute, Mauritskade 63, Amsterdam 1090 HA, The Netherlands.

\section{References}

1. Jones A, Howard N, Legido-Quigley H. Feasibility of health systems strengthening in South Sudan: a qualitative study of international practitioner perspectives. BMJ Open. 2015 Dec 1;5(12):e009296.

2. Erismann S, Gürler S, Wieland V, Prytherch H, Künzli N, Utzinger J, et al. Addressing fragility through community-based health programmes: insights from two qualitative case study evaluations in South Sudan and Haiti. Health Research Policy and Systems. 2019 Feb 14;17(1):20.

3. Health briefing note I UNICEF South Sudan. 2019. https://www.unicef.org/southsudan/reports/health-briefing-note. Accessed 18 Dec 2019

4. Checchi F, Testa A, Warsame A, Quach L, Burns R. South Sudan: Estimates of crisis-attributable mortality | LSHTM. 2018. https://www.Ishtm.ac.uk/research/centres/health-humanitarian-crises-centre/south-sudan-report-2018. Accessed 18 Dec 2019.

5. Piatti-Fünfkirchen M, Lindelow M, Yoo K. What Are Governments Spending on Health in East and Southern Africa? Health Systems \& Reform. 2018 Oct 2;4(4):284-99.

6. African Union. Abuja declaration on HIV/AIDS, tuberculosis and other related infectious diseases. OAU/SPS/Abuja/3. 2001;27. https://au.int/sites/default/files/pages/32904-file-2001_abuja_declaration.pdf. Accessed 10 Jan 2020.

7. South Sudan Health Policy 2012. https://www.google.com/search? q=South+sudan+Health+Policy+2012\&oq=South+sudan+Health+Policy+2012\&aqs=chrome..69i57j69i64.16320j0j8\&sourceid=chrome\&ie=UTF8. Accessed 18 Dec 2019.

8. Valadez JJ, Berendes S, Odhiambo J, Vargas W, Devkota B, Lako R, et al. Is development aid to strengthen health systems during protracted conflict a useful investment? The case of South Sudan, 2011-2015. BMJ Global Health. 2020 Apr 1;5(4):e002093.

9. Belaid L, Bayo P, Kamau L, Nakimuli E, Omoro E, Lobor R, et al. Health policy mapping and system gaps impeding the implementation of reproductive, maternal, neonatal, child, and adolescent health programs in South Sudan: a scoping review. Confl Health. 2020 Apr 14;14:20-20.

10. Declaration of Alma-Ata International Conference on Primary Health Care, Alma-Ata, USSR, 6-12 September 1978. Development. 2004 Jun;47(2):159-61.

11. WHO | Global Experience of Community Health Workers for Delivery of Health Related Millennium Development Goals: A Systematic Review, Country Case Studies, and Recommendations for Integration into National Health Systems.

https://www.who.int/workforcealliance/knowledge/resources/chwreport/en/. Accessed 18 Dec 2019

12. Walraven G. The 2018 Astana Declaration on Primary Health Care, is it useful? J Glob Health. 2019 Jun;9(1):010313-010313.

13. Gilmartin C, Collins D, Driwale A. South Sudan Boma Health Initiative Costing and Investment Case Analysis. 2019. Management Sciences for Health. Arlington, USA; 2019. https://www.unicef.org/southsudan/media/2026/file/South-Sudan-2019-BHI-Costing-Summary.pdf. Accessed 29 Dec 2019.

14. South Sudan Ministry of Health. The Community Health System in South Sudan: "The Boma Health System Initiative". A community anchored health system for sustainable health development. 2016.

http://www.arkangelo.org/AAA/AAA\%20documents/2016\%20documents/Boma\%20Health\%20Initiave\%20November\%20version.pdf. Accessed 18 Dec 2019.

15. The Department for International Development (DFID) and Global Affairs Canada. Evaluation of the South Sudan Health Pooled Fund. Integrity. 2018. http://iati.dfid.gov.uk/iati_documents/35675062.pdf. Accessed 10 Jun 2019.

16. Miller N. Community Case Management (CCM) in Humanitarian Settings: Global literature review. Resource Centre. 2019. https://resourcecentre.savethechildren.net/library/community-case-management-ccm-humanitarian-settings-global-literature-review. Access 9 Jan 2020.

17. Jervase A. Forty years of primary health care programming and its future in South Sudan. South Sudan Medical Journal. 2019 May 2;12:3677. 
18. Kok MC, Dieleman M, Taegtmeyer M, Broerse JE, Kane SS, Ormel H, et al. Which intervention design factors influence performance of community health workers in low- and middle-income countries? A systematic review. Health Policy Plan. 2015 Nov;30(9):1207-27.

19. World Health Organization2016. WHO | Global Strategy on Human Resources for Health: Workforce 2030. https://www.who.int/hrh/resources/globstrathrh-2030/en/. Accessed 10 Jan 2020.

20. Brown C, Lilford R, Griffiths F, Oppong-Darko P, Ndambo M, Okoh-Owusu M, et al. Case study of a method of development of a selection process for community health workers in sub-Saharan Africa. Human Resources for Health. 2019 Oct 25;17(1):75.

21. Olaniran A, Smith H, Unkels R, Bar-Zeev S, van den Broek N. Who is a community health worker? - a systematic review of definitions. Glob Health Action. 2017;10(1):1272223-1272223.

22. Scott K, Beckham SW, Gross M, Pariyo G, Rao KD, Cometto G, et al. What do we know about community-based health worker programs? A systematic review of existing reviews on community health workers. Human Resources for Health. 2018 Aug 16;16(1):39.

23. Condo J, Mugeni C, Naughton B, Hall K, Tuazon MA, Omwega A, et al. Rwanda's evolving community health worker system: a qualitative assessment of client and provider perspectives. Human Resources for Health. 2014 Dec 13;12(1):71.

24. World Population Review. Literacy Rate By Country 2020. http://worldpopulationreview.com/countries/literacy-rate-by-country/. Accessed 10 Jan 2020

25. World Health Organization. WHO Guideline on Health Policy and System Support to Optimize Community Health Worker Programmes. Geneva: World Health Organization. 2018. http://www.ncbi.nlm.nih.gov/books/NBK533329/. Accessed 30 Jan 2020.

26. O’Donovan J, Stiles CE, Sekimpi D, Ddumba I, Winters N, O'Neil Jr E. Potential challenges of implementing the Community Health Extension Worker programme in Uganda. BMJ Global Health. 2018 Aug 1;3(4):e000960.

27. Lehmann U, Sanders D. Community health workers: What do we know about them? The state of the evidence on programmes, activities, costs and impact on health outcomes of using community health workers | CHW Central. 2007. http://www.chwcentral.org/community-healthworkers-what-do-we-know-about-them-state-evidence-programmes-activities-costs-and. Accessed 11 Jan 2020.

28. McKague K, Harrison S. Gender and health social enterprises in Africa: a research agenda. Int J Equity Health. 2019 Jun 20;18(1):95-95.

29. Glenton C, Colvin CJ, Carlsen B, Swartz A, Lewin S, Noyes J, et al. Barriers and facilitators to the implementation of lay health worker programmes to improve access to maternal and child health: qualitative evidence synthesis. Cochrane Database Syst Rev. 2013 Oct 8;2013(10):CD010414-CD010414.

30. Wanduru P, Tetui M, Tuhebwe D, Ediau M, Okuga M, Nalwadda C, et al. The performance of community health workers in the management of multiple childhood infectious diseases in Lira, northern Uganda - a mixed methods cross-sectional study. Global Health Action. 2016 Dec 1;9(1):33194.

31. Rosato M, Laverack G, Grabman LH, Tripathy P, Nair N, Mwansambo C, et al. Community participation: lessons for maternal, newborn, and child health. The Lancet. 2008 Sep 13;372(9642):962-71.

32. Miller NP, Milsom P, Johnson G, Bedford J, Kapeu AS, Diallo AO, et al. Community health workers during the Ebola outbreak in Guinea, Liberia, and Sierra Leone. J Glob Health. 2018 Dec;8(2):020601-020601.

33. Kozuki N, Ericson K, Marron B, Lainez YB, Miller NP. The resilience of integrated community case management in acute emergency: a case study from Unity State, South Sudan. J Glob Health. 2018 Dec;8(2):020602.

34. Dynes M, Rahman A, Beck D, Moran A, Rahman A, Pervin J, et al. Home-based life saving skills in Matlab, Bangladesh: a process evaluation of a community-based maternal child health programme. Midwifery. 2011 Feb 1;27(1):15-22.

35. Nankunda J, Tumwine JK, Soltvedt Å, Semiyaga N, Ndeezi G, Tylleskär T. Community based peer counsellors for support of exclusive breastfeeding: experiences from rural Uganda. International Breastfeeding Journal. 2006 Oct 20;1(1):19.

36. Edward A, Branchini C, Aitken I, Roach M, Osei-Bonsu K, Arwal SH. Toward universal coverage in Afghanistan: A multi-stakeholder assessment of capacity investments in the community health worker system. Social Science \& Medicine. 2015 Nov 1;145:173-83.

37. CAPPS L, CRANE P. Evaluation of a programme to train village health workers in El Salvador. Health Policy and Planning. 1989 Sep 1;4(3):23943.

38. Glenton C, Scheel IB, Pradhan S, Lewin S, Hodgins S, Shrestha V. The female community health volunteer programme in Nepal: Decision makers' perceptions of volunteerism, payment and other incentives. Social Science \& Medicine. 2010 Jun 1;70(12):1920-7.

39. Najafizada SAM, Labonté R, Bourgeault IL. Community health workers of Afghanistan: a qualitative study of a national program. Conflict and Health. $2014 \operatorname{Dec} 1 ; 8(1): 26$.

40. Westgard C, Naraine R, Paucar Villacorta D. Performance Evaluation of Community Health Workers: Case Study in the Amazon of Peru. Journal of Community Health. 2018 Mar 26;43.

41. Majidi S, Daneshkohan A, Zarei E, Ashktorab T. Perspectives of health workers on annual performance appraisal: A study in primary health care. International Journal of Healthcare Management. 2020 Apr 28;1-8.

42. Agarwal S, Sripad P, Johnson C, Kirk K, Bellows B, Ana J, et al. A conceptual framework for measuring community health workforce performance within primary health care systems. Human Resources for Health. 2019 Nov 20;17(1):86.

Page $12 / 13$ 
43. Baatiema L, Skovdal M, Rifkin S, Campbell C. Assessing participation in a community-based health planning and services programme in Ghana. BMC Health Services Research. 2013 Jun 26;13(1):233.

44. Laverack G. Improving Health Outcomes through Community Empowerment: A Review of the Literature. Journal of Health, Population and Nutrition. 2006;24(1):113-20.

45. Wallerstein N. Powerlessness, Empowerment, and Health: Implications for Health Promotion Programs. Am J Health Promot. 1992 Jan 1;6(3):197-205.

46. Rappaport J. Terms of empowerment/exemplars of prevention: Toward a theory for community psychology. American Journal of Community Psychology. 1987 Apr 1;15(2):121-48.

47. Schaaf M, Warthin C, Freedman L, Topp SM. The community health worker as service extender, cultural broker and social change agent: a critical interpretive synthesis of roles, intent and accountability. BMJ Global Health. 2020 Jun 1;5(6):e002296.

48. Zakus JDL, Lysack CL. Revisiting Community Participation. Health Policy and Planning. 1998 Mar 1;13(1):1-12.

49. Sakeah E, McCloskey L, Bernstein J, Yeboah-Antwi K, Mills S, Doctor HV. Is there any role for community involvement in the community-based health planning and services skilled delivery program in rural Ghana? BMC Health Services Research. 2014 Aug 11;14(1):340.

50. Lehmann U, Twum-Danso NAY, Nyoni J. Towards universal health coverage: what are the system requirements for effective large-scale community health worker programmes? BMJ Global Health. 2019 Oct 1;4(Suppl 9):e001046.

51. Simon S, Chu K, Frieden M, Candrinho B, Ford N, Schneider H, et al. An integrated approach of community health worker support for HIV/AIDS and TB care in Angónia district, Mozambique. BMC International Health and Human Rights. 2009 Jul 17;9(1):13.

52. Chang LW, Kagaayi J, Arem H, Nakigozi G, Ssempijja V, Serwadda D, et al. Impact of a mHealth Intervention for Peer Health Workers on AIDS Care in Rural Uganda: A Mixed Methods Evaluation of a Cluster-Randomized Trial. AIDS and Behavior. 2011 Jul 8;15(8):1776.

53. Rosales AC, Walumbe E, Anderson FWJ, Hedrick JA, Cherian DT, Holloway R. Role of an international non-governmental organisation in strengthening health systems in fragile-state context: Evaluation results from South Sudan. African Evaluation Journal; Vol 3, No 2 (2015) DO 104102/aej.v3i2162. 2015 Oct 12. https://aejonline.org/index.php/aej/article/view/162/230

54. Ruckstuhl L, Lengeler C, Moyen JM, Garro H, Allan R. Malaria case management by community health workers in the Central African Republic from 2009-2014: overcoming challenges of access and instability due to conflict. Malaria Journal. 2017 Sep 29;16(1):388. 